\title{
The impact of tobacco tax reforms on poverty in Mexico
}

\author{
Luis Huesca ${ }^{1}$ (D) Abdelkrim Araar $^{2}$ (D) - Linda Llamas ${ }^{3}$ (D) Guy Lacroix $^{2}$ (D)
}

Received: 22 March 2021 / Accepted: 17 August 2021 / Published online: 22 September 2021

(c) The Author(s), under exclusive licence to Springer Nature Switzerland AG 2021

\begin{abstract}
This paper investigates the impact of increasing the tobacco taxes on the poverty rate in Mexico. Unlike most LMIC countries, the prevalence of smoking in Mexico is higher among the well-off than among the poor. Yet, tobacco tax rates in Mexico are lower than those in most LMIC countries. There is room, thus, to implement tax reforms and compensating policies to mitigate their impact on the poor. Our analysis is based on the stochastic dominance approach. More precisely, several tax reforms are analyzed through the so-called Consumption Dominance curves. In addition, the reforms are assumed to be revenue neutral and to give rise to compensating subsidies on specific goods. Our results show that if the Mexican government were to implement a WHO-type reform, poverty among households with at least one smoking member would increase by $2.6 \%$ points. Yet, the deleterious effects are entirely mitigated by price subsidies on staple foods.
\end{abstract}

Keywords Tobacco taxation $\cdot$ Impact analysis $\cdot$ Excise taxes $\cdot$ Poverty $\cdot$ Stochastic dominance

JEL Classification D31 $\cdot$ D63 $\cdot$ I32 $\cdot$ I38

Luis Huesca

lhuesca@ciad.mx

Abdelkrim Araar

Araar.Abdelkrim@ecn.ulaval.ca

Linda Llamas

linda.1lamas@gmail.com

Guy Lacroix

Guy.Lacroix@ecn.ulaval.ca

1 Centro de Investigación en Alimentación y Desarrollo, CIAD, Guaymas, Mexico

2 Department of Economics, Université Laval, Quebec City, Canada

3 Universidad Estatal de Sonora, UES, Hermosillo, Mexico 


\section{Introduction}

The economies of most Latin American countries depend heavily on exports from primary sectors such as raw materials, oil, and energy. In recent years, they have had to contend with falling international prices, in addition to the current outbreak of the SARS-CoV-2 pandemic, all the while insuring minimal provision of health services, pensions for the elderly, and education for the youth. In Mexico, excise taxes are particularly important because of the limited collection capacity of the central government and the narrow margins for additional revenues levied on earnings or consumption.

Amid this turmoil, the Mexican government has recently implemented a number of tax reforms aimed at curbing various public health issues. Chief among them is the introduction of an excise tax on high-calorie sugary drinks deemed partly responsible for the prevalence of obesity. Another major public health concern is tobacco consumption. Yet, tobacco taxation has remained constant since 2001 despite the fact it is acknowledged to be the most cost-effective policy to reduce consumption, decrease the associated health burden, and increase tax revenues (Chaloupka et al. 2012). The 2020 tax reform on tobacco is predicted to increase revenues only marginally from its current level of $9.3 \%$ (Huesca et al. 2019, 2020).

Mexico stands out from other Low- and Middle-Income Countries (LMIC) in that smoking is much less prevalent among low-income groups (Chaloupka and Blecher 2018; Ross et al. 2006). Indeed, smoking among high-income groups is three-to-four times more prevalent (Huesca et al. 2019). Hence, increasing tax rates on tobacco may impact poverty less than in countries such as the Russian Federation, Ukraine, Vietnam, the Philippines, etc.

The tobacco excise tax in Mexico is composed of two parts: an ad valorem tax and a specific per cigarette tax. The latter component aims at discouraging consumers to choose cheaper cigarettes. The specific tax was introduced in 2010 and had a minimal effect. In 2008 , the tobacco excise tax was equivalent to $52 \%$ of the final consumer price ( $65 \%$ with the VAT). However, a specific tax of $\$$ 0.04 pesos per cigarette was implemented in 2010, so that the total tax burden then accounted for $63 \%$ of the retail price. By 2012, the specific tax was set at $\$ 0.35$ pesos per cigarette, increasing the total tax burden to as much as $67 \%$. Both remained constant until 2018 (WHO 2009, 2011, 2013, 2015, 2019). The 2020 tobacco tax reform is of limited scope as it only aligns the specific component to the rate of inflation (from 0.35 to 0.49 cents per cigarette) and is not expected to increase tax revenues nor to reduce smoking substantially (Huesca et al. 2020). As a result, the combined share of the excise tax and the VAT will still be well below $75 \%$ of the final price, which is the benchmark recommended by the WHO since 2005. In most developed and LMIC countries, taxes amount to, or are above, $75 \%$ of the final cigarette price (WHO 2015).

The poverty rate in Mexico is currently relatively high at $48 \%$ of its population (CONEVAL 2019b). This paper aims at estimating the likely impact of several potential tobacco tax reforms on poverty. More precisely, we analyze four 
different scenarios in which the ad valorem and the specific taxes are progressively increased until they amount to $75 \%$ of the final price or slightly above as in other LMIC countries. There is ample evidence, showing that increases in cigarette prices tend to crowd out expenditures on basic necessities as witnessed in Cambodia, Turkey, and Bangladesh (Ross et al. 2012; Husain et al. 2018). The four scenarios we analyze are constrained to be revenue neutral for two reasons. First, transferring the tax proceeds from richer to poorer households will mitigate the negative crowding-out effects. Second, tax-neutral reforms may be more socially acceptable and are likely to be implemented. The manner in which the tax proceeds are transferred to poor households is also a major policy concern. International evidence shows that income transfers are oftentimes used for out-ofpocket healthcare expenditures (Chaloupka and Blecher 2018; CONEVAL 2019b; Fuchs et al. 2017). Yet, over the past decade, poor Mexican households have benefited at no cost from better healthcare and drugs coverage through the Instituto Mexicano del Seguro Social (IMSS). Our analysis instead identifies consumption goods that could be subsidized and which have the best potential to mitigate the deleterious effects of the tobacco tax.

Our analysis is based on the so-called Consumption Dominance (CD) curves. These are estimated before and after the implementation of each tax scenario to identify who would be hurt most. Assuming tax neutrality, we can then determine the implicit subsidy on specific consumption items that would leave poor households almost as well-off once the tax hike is implemented. Our results show that if the Mexican government were to implement a WHO-type reform, the poverty rate among households with a least one smoking member would increase by $2.6 \%$ points. Under reasonable assumptions, we find that the impacted households could be compensated by the implementation of a subsidy on the specific food staples of typical Mexican households such as beans, corn-tortillas, and eggs. Subsidizing milk products would also be efficient but to a lesser extent. Not surprisingly, subsidizing health care expenditures will have next to no effect on poverty given the recent availability of better health care coverage and because our preliminary investigations that are based on expenditures' shares show that poor use less the paid health services.

The paper is organized as follows. The next section presents the data and the methodological approach. The third section describes the four tax scenarios and discusses the computation of the Consumption Dominance curves. The fourth section discusses the empirical and simulation results. We conclude the paper in the fifth section.

\section{Data and methodological approach}

\section{Data}

Data from the 2016 National Household of Income and Expenditure Survey (ENIGH for its acronym in Spanish) (John et al. 2012) were used for this analysis. We use the term tobacco to refer to household consumption of cigarettes only, as 
usual in the literature. The total sample consists of 70,309 observations of which 3,901 are smokers. The sample is drawn using a two-stage stratified probabilistic design and so is representative at the national level as well as for urban and rural strata. The ENIGH 2016 surveys cross-sectional units and allows the identification of household income and expenditures, including the expenditure made on tobacco. In this study, these variables are expressed in Mexican pesos per capita (PC) at 2016 prices.

Total expenditures are obtained from the monetary expenditures made on all goods and services for own consumption and use. Subsequently, only the expenditures made on tobacco are subtracted to compute its tax burden. However, because ENIGH does not provide the pre-tax price for cigarettes, a conversion scale is adopted based on the amount purchased and is reported in kilograms in the survey. Following a previous study, we use the Marlboro 20-cigarette pack for this purpose as it is the most consumed in Mexico (San and Chaloupka 2016). Considering that the unit weight of the cigarette is 1.25 grams, the conversion scale to approximate the price of the package is obtained as follows:

$$
(1000 \text { grams } / 1.25 \text { grams }) / 20 \text { cigarettes }=40 \text { packs } .
$$

For the calculation of indirect taxes on tobacco (Value-Added Tax and Excise, VAT and IEPS respectively), an indirect allocation method is used in line with fiscal rules applicable to the survey year 2016. Other surveys that capture specific information on cigarettes and tobacco products may provide a more precise analysis of consumption on the black market or with respect to the point of sales. However, this limitation is not a matter of concern as it will not change the results and conclusions of the model.

\section{Estimation of poverty}

Household poverty level in 2016 stood at $43.6 \%$ equivalently to 53.4 million poor in 2016. The calculation of the poverty levels of smokers and non-smokers was disaggregated by location (urban and rural) in accordance with the official welfare poverty criteria conducted by the National Council for the Evaluation of Social Development Policy (INEGI 2017). Thus, in 2016, the poverty line in PC units per year for urban areas was 32,393.09 pesos (about \$1,568 US), while for rural areas, it corresponded to $20,931.35$ pesos (about $1,013 \mathrm{US}$ ). The poverty rate for the whole population at the household level was $41 \%$. On the other hand, the poverty level among smokers was only 34\% (see Table B.1 in Appendix B).

\section{Methodology}

Our analysis is based on the so-called Consumption Dominance Poverty Curves $(C D)$, originally proposed by Makdissi and Wodon (2002) and further shown to be relevant to the analysis of socially improving indirect tax reforms by Duclos et al. (2008). The CD is intimately related to the well-known Foster-Greer-Thorbecke (FGT) family of poverty indices (Makdissi and Wodon 2002). Thus, first define 


$$
D(z, s)=\int_{0}^{z}\left(\frac{z-y}{z}\right)^{s-1} d F(y)
$$

as an (continuous) index of a social order of dominance $s$, where $z$ stands for poverty line $\left[0, z^{+}\right]$and $y$ is the level of income. The poverty dominance curve $D(z, s=\alpha+1)$ for a given level of the poverty line is simply the $F G T(z, s=\alpha)$ measurement at that poverty line.

For a given good, $g$, the consumption dominance curve $C D_{g}(z, s=\alpha+1)$ is defined as the marginal impact of an increase in its price on the $F G T(z, s=\alpha)$ index, that is

$$
C D_{g}=\frac{\partial D(z, s=\alpha+1)}{\partial p_{g}},
$$

where $p_{g}$ is the unit price of good $g$. The comparison between poverty dominance curves can be used to establish an ordinal classification of poverty and is thus intimately related to the study of poverty dominance (Foster and Shorrocks 1988a; Makdissi and Wodon 2002). ${ }^{1}$

Analyses conducted on the basis of CD curves are rather novel and improve upon traditional FGT indices. Indeed, the approach allows to quantify poverty changes for a whole array of thresholds, and up to the point where poverty is eradicated. As with any poverty analysis, it rests upon social-ethical orders. In what follows, we provide normative details and show how the approach can be implemented in the context of fiscal reforms.

A. Poverty dominance and the social-ethical orders

A tax reform will naturally induce a change in the distribution of well-being or income. The notion of social welfare improvement refers to the welfare/poverty dominance of the post-reform distribution (Duclos et al. 2008). Yet, welfare dominance is also defined according to a specific social order, i.e., a set of socialethical judgments that society adopts as a social norm. These can be related to poverty indices as follows:

1. First-order: poverty indices must remain unchanged or decrease whenever $y_{i}$ increases. This class of indices satisfies the so-called anonymity axiom.

2. Second-order: poverty indices belong to the first-order set. In addition, they must obey the Pigou-Dalton principle: transferring income from a higher to a lower income individual must reduce the poverty index (sensitivity to inequality among the poor). Thus, a neutral tax reform involves maintaining or even improving social welfare by transferring additional tax revenues accruing from higher incomes to avoid the crowding-out effect on the poor.

\footnotetext{
1 For the first-order dominance, the CD for a given poverty line will simply be the estimate of the change in both the headcount poverty $(\alpha=0)$ and the poverty gap $(\alpha=1)$ implied by the tax reform. This change will depend on the density curve of $y$ as well as on the level of consumption of tobacco of the group whose incomes are in the neighborhood of the poverty line.
} 
3. Third-order: poverty indices belong to the second-order set. In addition, poverty indices must decrease with the following composite transfer: a beneficial Pigou-Dalton transfer within the lower part of the income distribution accompanied by an adverse Pigou-Dalton transfer within the upper part of the distribution must be such that the variance of the distribution must not increase.

4. $s$-order: belong to the $s-1$ order. As a general rule, the higher the order of the class, the higher the sensitivity of the indices to a change in the standard of living of the poor.

Indices belonging to the four definitions above are said to be Pen-improving, Dalton-improving, Kolm-improving, and higher order welfare-improving, respectively. In each case, the analysis requires that an arbitrary poverty line or minimal cost-of-living be determined a priori. We use that of CONEVAL (2019a) to ease comparability with official poverty estimates.

B. Economic efficiency of a tax reform

Economic efficiency refers to the change in the average welfare cost of the new tax burden imposed upon consumers, so that it corresponds to 1 minus the social deadweight loss of taxing the preferred good. Let $\overline{C D}$ curves represent "the ethically weighted (or social) cost of taxing good $k$ as a proportion of the average welfare cost ... where the social cost depends on the values of $s$ and $z$ " (Duclos et al. 2008) [p.1514]. To compute changes in poverty due to a marginal tax reform, we must use "normalized" $\overline{C D}$ curves which are defined as

$$
\overline{C D}_{k}(z, s)=\frac{\partial D(z, s) / \partial t_{k}}{X_{k}},
$$

where $t_{k}$ is the proportional increase in price of good $k$ following a tax increase, and where $X_{k}$ is the share of average consumption of the good in the population. The expression corresponds to the change in the ethically weighted sum of deprivation (the usual dominance curve, $D^{s}(z)$ ), normalized by the average consumption of good $k$.

C. Socially improving neutral tax reform

For simplicity, assume that all of the prices are normalized to 1 prior to the fiscal reform. As above, denote the average per capita (PC) expenditures-or quantity-on good $k$ by $X_{k}(p)$, and where $p$ is the vector of prices. The postreform $\mathrm{PC}$ tax revenue is

$$
R(p)=\sum_{k-1}^{K} t_{k} X_{k}(p) .
$$

A neutral tax reform involves increasing the tax rate on good $j$ (tobacco for instance) and simultaneously decreasing the tax rate (or increasing the subsidy) on good $l$, in such a way that $d R(p)=0$. Totally differentiating Eq. (4), we get 


$$
d R(p)=\left[X_{j}(p)+\sum_{k=1}^{K} t_{k} \frac{\partial X_{k}(p)}{\partial p_{j}}\right] d p_{j}+\left[X_{l}(p)+\sum_{k=1}^{K} t_{k} \frac{\partial X_{k}(p)}{\partial p_{l}}\right] d p_{l}
$$

The economic efficiency cost, $\gamma_{l j}$, corresponds to the ratio of the cost of taxing good $j$ relative to that of taxing (or subsidizing) good $l$-a necessary good

$$
\gamma_{l j}=\frac{\left[X_{l}(p)+\sum_{k=1}^{K} t_{k} \frac{\partial X_{k}(p)}{\partial p_{j}}\right] / X_{l}(p)}{\left[X_{j}(p)+\sum_{k=1}^{K} t_{k} \frac{\partial X_{k}(p)}{\partial p_{j}}\right] / X_{j}(p)} .
$$

In the extreme case where all goods are perfectly inelastic, then the efficiency cost is equal to 1 .

D. Changes in poverty and neutral tax reform

Consider a marginal income-neutral tax reform on tobacco. Such a reform will be welfare-improving if the following holds:

$$
\overline{C D}_{l}(s, y)-\gamma_{l j} \overline{C D}_{j}(s, y) \geq 0, \forall y \in\left[0, z^{+}\right],
$$

where $\overline{C D}_{l}(s, y)$ is defined in Eq. (3). Equation (7) states that the reform must be s-order poverty improving for all poverty lines between 0 and $z^{+}$. It can be shown that the above inequalities will be satisfied if good $q_{j}$ and price $p_{j}$ are such that

$$
d q_{j}=-\gamma_{j l} \frac{X_{l}}{X_{j}} d q_{l} \text { and } d p_{j}=-\gamma_{j l} \frac{X_{l}}{X_{j}} d p_{l}
$$

Define $\delta_{l j}(z, s)$ as

$$
\delta_{l j}(z, s)=\frac{\overline{C D}_{l}(z, s)}{\overline{C D}_{j}(z, s)}
$$

which is reminiscent of the well-known normalized ratio of Engel curves. A sufficient condition for an income-neutral tax reform to be s-order poverty improving is given by

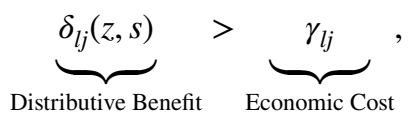

for all $z \in\left[0, z^{+}\right]$. Thus, $\delta_{l j}(z, s)$ corresponds to the ratio of $\overline{C D}_{l j}(z, s)$ for each pair of commodities and for any poverty line. From the above, it follows that the higher $\gamma_{l j}$ is, the less efficient it is to $\operatorname{tax} \operatorname{good} j$ (tobacco). 
Table 1 Cigarette consumption and household economic status, Mexico 2016

Quintile of PC income

Economic status

\begin{tabular}{|c|c|c|c|c|c|c|}
\hline & \multicolumn{4}{|c|}{ Poorest } & \multirow{2}{*}{$\begin{array}{l}\text { Richest } \\
5\end{array}$} & \multirow{2}{*}{$\begin{array}{l}\text { Smok- } \\
\text { ing pop. } \\
\text { total }\end{array}$} \\
\hline & 1 & 2 & 3 & 4 & & \\
\hline$\%$ Households that smoke & $3.3 \%$ & $4.9 \%$ & $5.2 \%$ & $6.5 \%$ & $7.2 \%$ & $5.6 \%$ \\
\hline $\begin{array}{l}\text { Average monthly consumption } \\
\text { of cigarettes (packs)/adult }\end{array}$ & 3.5 & 3.5 & 2.7 & 2.0 & 2.2 & 2.8 \\
\hline Share of cigarette expenditures & $4.9 \%$ & $3.5 \%$ & $2.3 \%$ & $1.8 \%$ & $1.0 \%$ & $2.7 \%$ \\
\hline On household income & & & & & & \\
\hline
\end{tabular}

Source: Author's calculations using ENIGH 2016

\section{Empirical strategy and results}

For the first-order dominance of class $s$, the $C D(z, s)$ for a given poverty line corresponds to the change in both the poverty headcount $(s=1)$ and the poverty gap $(s=2)$ implied by the tax reform. Our empirical strategy involves several steps. First, we proceed to estimate the expected level of consumption of cigarettes for those whose incomes are within a certain neighborhood of the poverty line. To this end, we use standard non-parametric regressions so as not to impose particular functional relationships in the data. Likewise, we use a (kernel) non-parametric approach to obtain precise estimates of the density of income in the neighborhood of the poverty threshold. The effect of the price change due to an increase in the tobacco tax on poverty is measured by (minus) the product of the latter two estimates (Makdissi and Wodon 2002). Next, we perform the dominance tests to inquire whether the social efficiency of the neutral income tax reforms is poverty reducing. Finally, the construction of the $\mathrm{CD}$ curves is obtained from the computation of poverty estimates for a wide range of poverty lines. ${ }^{2}$

\section{Prima facie evidence}

Table 1 reports the main stylized facts about income and smoking in Mexico. Columns 1-5 are organized in increasing order of household income quintiles. The proportion of households with at least one smoker increases more than twofold from the lowest to the highest quintiles. This is in line with recent evidence for Mexico (Chaloupka and Blecher 2018; San and Chaloupka 2016; Foster et al. 1984). Despite the fact that the average number of cigarette packs consumed per adult if inversely related to income, total consumption is nevertheless positively related to

\footnotetext{
${ }^{2}$ All calculations are done with Stata version 15.1 and the DASP modules. For more details, see (Araar et al. 2011).
} 
Table 2 Tax scheme for tobacco and simulation of reforms

\begin{tabular}{llllll}
\hline Tax components & Initial & $S_{1}$ & $S_{2}$ & $S_{3}$ (WHO) & $S_{4}$ (Int.Pr) \\
\hline 1: Ad-valorem excise tax (on base 0) & $160 \%$ & $160 \%$ & $240 \%$ & $260 \%$ & $240 \%$ \\
2: Specific excise tax per cigar (on base 1) & 0.35 & $\$ 1.35$ & $\$ 0.35$ & $\$ 0.80$ & $\$ 2.35$ \\
3: Value added tax (on base 2) & $16 \%$ & $16 \%$ & $16 \%$ & $16 \%$ & $16 \%$ \\
\hline
\end{tabular}

1: Base $0=$ Price without taxes 2: Base $1=$ Base $0+$ Ad-valorem excise tax 3: Base $2=$ Base $1+$ Specific excise tax (expressed in Mexican pesos) Source: own elaboration based on SHCP Law on Special Tax and Services

the latter. This in stark contrast to most low and middle-income countries where the prevalence of smoking is highest among the low-income population (Chaloupka and Blecher 2018). In a sense, as formulated by Duclos et al. (2014), this is fortunate as it provides an opportunity to tax the richer at a presumably lower societal cost by simply assessing a tax reform able to increase social welfare according to functions valuated as second-order social welfare functions.

\section{Tobacco tax scenarios}

We consider four distinct scenarios as detailed in Table 2. Scenarios 1 and 2 are deemed more conservative, whereas Scenarios 3 and 4 are more in line with the WHO recommendations. Indeed, both would bring the selling price in Mexico at par with those in countries with similar or higher levels of economic development.

For each scenario, the estimated average changes in the tobacco price were obtained from a cigarette demand model (see first paragraph of Sect. 3). ${ }^{3}$ The estimated price changes per cigarette pack are, respectively: $S_{1} \approx 6.36 \% ; S_{2} \approx 30.08 \%$; $S_{3} \approx 40.78 \% ; S_{4} \approx 42.80 \%$. Moreover, the tobacco tax burden (including the VAT) under $S_{4}$ amounts to over $78 \%$ of the final sales price. Both $S_{3}$ and $S_{4}$ induce the largest price increases and thus may potentially modify consumption and the levels of poverty the most. Most importantly, note that specific excise taxes can exert a higher impact on tobacco consumption by preventing substitutions to cheaper brands. The ad valorem tax is expressed as a percentage of the pre-tax price and the specific component is applied to each cigarette separately.

\section{Impact on poverty}

Table 3 reports the changes in poverty under each scenario. These are computed according to headcount $(C D(z, s=1))$, poverty gap $(C D(z, s=2))$, and poverty severity, respectively (square poverty gap). Recall that the two-step procedure refers to the fact that the expected level of consumption of cigarettes in a certain neighborhood of the poverty line is first computed, and the density of income in the same neighborhood is computed next. The effect of the price change on poverty is measured by (minus) the product of the latter two estimates. The one-step procedure

\footnotetext{
3 The results are omitted for the sake of brevity, but are available as a web companion.
} 
Table 3 Impact on poverty for tobacco tax scenario in Mexico, 2016

\begin{tabular}{|c|c|c|c|c|c|c|c|c|c|c|c|c|c|c|c|c|c|c|}
\hline \multirow[t]{3}{*}{ Scenario } & \multicolumn{6}{|c|}{ Headcount } & \multicolumn{6}{|c|}{ Poverty gap } & \multicolumn{6}{|c|}{ Square poverty gap } \\
\hline & \multicolumn{6}{|c|}{0.3192} & \multicolumn{6}{|c|}{0.1444} & \multicolumn{6}{|c|}{0.0702} \\
\hline & \multicolumn{2}{|c|}{$\begin{array}{l}\text { Two } \\
\text { steps }\end{array}$} & \multicolumn{2}{|c|}{$\begin{array}{l}\text { One } \\
\text { step CD } \\
\text { curve }\end{array}$} & \multicolumn{2}{|c|}{$P$-value } & \multicolumn{2}{|c|}{$\begin{array}{l}\text { Two } \\
\text { steps }\end{array}$} & \multicolumn{2}{|c|}{$\begin{array}{l}\text { One } \\
\text { step CD } \\
\text { curve }\end{array}$} & \multicolumn{2}{|c|}{$P$-value } & \multicolumn{2}{|c|}{$\begin{array}{l}\text { Two } \\
\text { steps }\end{array}$} & \multicolumn{2}{|c|}{$\begin{array}{l}\text { One } \\
\text { step } \\
\text { CD } \\
\text { curve }\end{array}$} & \multicolumn{2}{|c|}{$P$-value } \\
\hline$S_{1}$ & 0 & 004 & 0 & 004 & 0 & 413 & 0 & 002 & 0 & 002 & 0 & 000 & 0 & 002 & 0 & 001 & 0 & 000 \\
\hline$S_{2}$ & 0 & 014 & 0 & 019 & 0 & 026 & 0 & 011 & 0 & 010 & 0 & 000 & 0 & 006 & 0 & 006 & 0 & 000 \\
\hline$S_{3}$ & 0 & 025 & 0 & 026 & 0 & 001 & 0 & 015 & 0 & 014 & 0 & 000 & 0 & 009 & 0 & 008 & 0 & 000 \\
\hline$S_{4}$ & 0 & 026 & 0 & 027 & 0 & 000 & 0 & 016 & 0 & 015 & 0 & 000 & 0 & 010 & 0 & 008 & 0 & 000 \\
\hline
\end{tabular}

Source: Authors'calculations using ENIGH survey, 2016 and scenarios for tobacco tax

refers to the fact that we differentiate the pre- and the post-CD curves departing from its initial level of $31.92 \%$. $^{4}$

Although changes in poverty are relatively small, the more aggressive scenario $S_{4}$ nevertheless has a sizable impact of 2.6 percentage point change. Yet, such small changes in poverty are consistent with the fact that the density of households with at least one smoker near the official poverty line in Mexico is relatively low. Hence, smokers at the threshold who may fall into poverty would reach at most 2.6 points of change, that is, 48,250 households representing approximately 209,888 individuals. Although the increase in poverty is small, it is no less important. Indeed, these individuals would add to the existing level of poverty, so that the total number household with a smoker in poverty under $S_{4}$ would reach $34.5 \%$ (representing 658,713 households or roughly 2.8 million individuals).

\section{Consumption dominance curves}

As mentioned above, changes in poverty can also be estimated directly by a comparison between $C D(z, s)$ curves. Additionally, they allow computing tax-neutral changes in poverty. Figure $1 \mathrm{a}-\mathrm{d}$ depicts the differences in the $C D(z, s=1)$, i.e., $\overline{(C D)}$, curves for scenarios $S_{1}, S_{2}, S_{3}, S_{4}$, respectively. The resulting increases in poverty are almost identical to those of the two-step approach. Thus, scenarios $S_{1}$ and $S_{2}$ hardly increase the poverty rate. On the other hand, scenarios $S_{3}$ and $S_{4}$ yield sizable increases in poverty. While both approaches yield similar results, the consumption dominance curves are preferable to the two-step method from a purely methodological point of view, since the latter is only valid locally, i.e., in the neighborhood of the poverty line.

Clearly, under a money metric utility framework, increasing a tax rate or the price of a given good will translate into lesser individual well-being and could eventually lead to increases in poverty. However, this can be mitigated if low-income

\footnotetext{
${ }^{4}$ See decomposition of poverty for smokers in Table B.1 in Appendix B.
} 
(a) $S_{1}(z, s=1): 0.4 \%$ poor

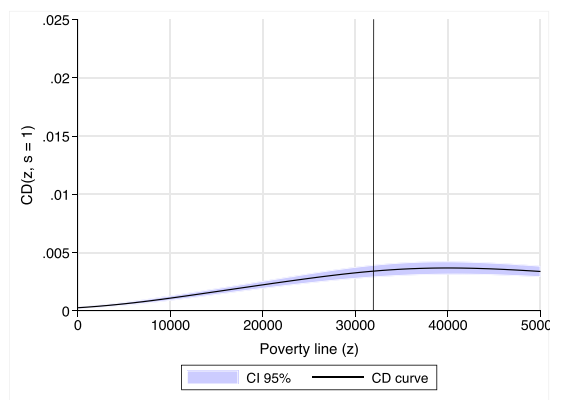

(c) $S_{3}(z, s=1): 2.5 \%$ poor

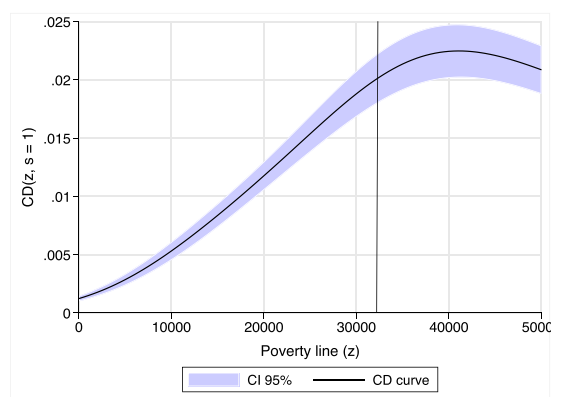

(b) $S_{2}(z, s=1): 1.4 \%$ poor

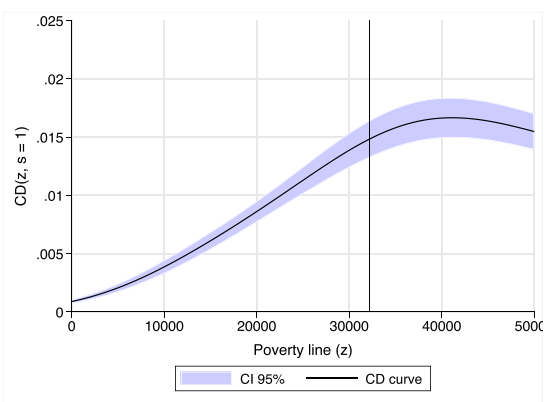

(d) $S_{4}(z, s=1): 2.6 \%$ poor

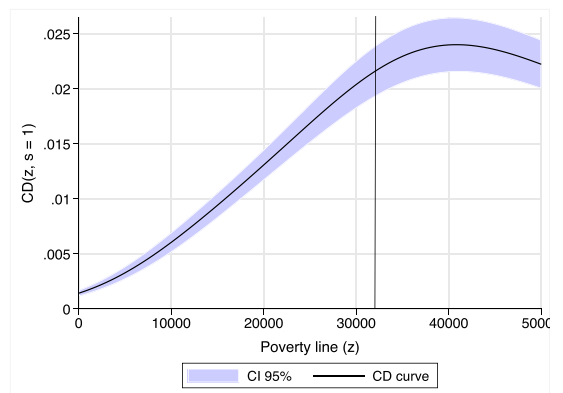

Fig. 1 Dominance consumption curves on tobacco and changes in poverty in Mexico, 2016. Source: Authors' estimation

households have proportionately lower expenditures on tobacco. In addition, recent evidence suggests that poor parents in Mexico behave altruistically toward their children as those who benefit from public programs tend to spend more on children goods without increasing their expenditures on adult goods (Schluter and Wahba 2010). Hence, additional government revenues accruing from the increase in the tobacco tax could be welfare-enhancing if provided to poor households through additional transfers. We next investigate how such transfers may alleviate poverty.

The $C D$ curves depicted in Fig. 1 move upward for a given $z$ as we move from Fig. 1a-d. Note that the lower bounds of the confidence interval of $S_{3}$ and $S_{4}$ (Fig. 1c-d) do not overlap with the upper bounds of $S_{1}$ and $S_{2}$ (Fig. 1a, b) at the official (vertical) poverty line. While Fig. 1c, d is similar in shape, they have somewhat different policy implications. Indeed, under $S_{4}$, the government reaps more tax revenues and thus has more leeway for alternative policies.

\section{Transfers as a uniform subsidy among poor smokers}

Recall that scenarios $S_{3}$ and $S_{4}$ yield the largest increases in poverty among smokers. Yet, these scenarios mimic the WHO's recommendation $\left(S_{3}\right)$ or align the tobacco 
prices in Mexico with those of countries exhibiting similar economic development $\left(S_{4}\right)$. While they increase poverty most, they also yield the greatest increases in tax revenues. We thus wish to investigate their net impact on poverty was the latter revenues spent according to the current government budget expenditures. More specifically, we consider the consequences of spending that additional tax revenues in three different budget items: (1) health expenditures targeted toward smoking-related illnesses; (2) in-kind transfer program to support the marginal new poor households; (3) public programs to raise awareness about the deleterious consequences associated with smoking.

Several fundamental elasticities are required to compute the net impact of all four tax scenarios $S_{1} \ldots S_{4}$. We estimate the price-elasticity of tobacco using a two-part equation as in Jimenez-Ruiz et al. (2008) and obtain an estimate of -0.503 (See Appendix A for details). Elasticity estimates of health expenditures and basic food items and milk for Mexico are set at -0.90 and -1.25 , respectively, and are borrowed from the recent literature (de Miera et al. 2013). As a first step, we calculate the parameter $\gamma$ for each scenario. ${ }^{5}$ We consider per capita expenditures on health, milk, as well as a bundle of four basic products consumed mostly by the poor households (milk, egg, corn tortilla and beans). Based on these elasticities and PC expenditures, we can compute the associated $\delta$ 's and $\gamma$ 's. These are also reported in Table 4. The column entitled "Change required in price of ..." refers to the necessary change (subsidy) for a given increase in the tobacco tax to keep the government tax revenues constant (subsidy). As shown in the table, the best options for poor households consist in milk as well as a bundle of basic food items. Indeed, expenditures on these goods are highly concentrated among households in low-income quintiles (Huesca et al. 2019).

It is important to recall that the neutral tax reform will reduce poverty without sacrificing resources from earmarked revenues if and only if the following relation holds [see Eq. (10)]:

$$
\delta_{l j}=\frac{C D_{l}(\text { subsidy })}{\left.C D_{j} \text { (tobacco }\right)} .
$$

If this condition holds, the distributive benefit of the tobacco tax is greater than its economic cost. The last column of Table 4 reports the estimates of $\gamma$, which is greater than 1 in all cases, as expected.

In addition, the $\delta_{l j}$ ratio for the each good should be greater than $\gamma_{l j}$ if the tax scenarios are progressive. Based on the foregoing, we use the estimate for the bundle of basic food with a value of 1.37 as a baseline, since this expenditure has the greatest average share among the poor and thus possesses the best redistributive potential (see Table 3, last line). In Fig. 2a and b, it is readily apparent that providing a subsidy for either milk or for a bundle of food does indeed compensate smokers from poor households located to the left of the poverty threshold (vertical dashed line).

\footnotetext{
${ }^{5}$ See Eq. (A7) and (A8) in appendix (A) for details.
} 
Table 4 Uniform transfer and subsidy for change in tobacco taxes and scenarios in Mexico (neutral tax reform)

\begin{tabular}{|c|c|c|c|c|c|}
\hline Health & $\begin{array}{l}\text { Average PC } \\
\text { expenses on } \\
\text { tobacco }\end{array}$ & $\begin{array}{l}\text { Average PC } \\
\text { expenses on } \\
\text { health }\end{array}$ & $\begin{array}{l}\text { Change in } \\
\text { price of } \\
\text { tobacco }\end{array}$ & $\begin{array}{l}\text { Change required } \\
\text { in price of health }\end{array}$ & Parameter $\gamma$ (costs) \\
\hline Scenario 1 & 220.5 & 836.2 & 0.064 & -0.0047 & 1.0415 \\
\hline Scenario 2 & 220.5 & 836.2 & 0.301 & -0.0189 & 1.2227 \\
\hline Scenario 3 & 220.5 & 836.2 & 0.408 & -0.0237 & 1.3230 \\
\hline Scenario 4 & 220.5 & 836.2 & 0.428 & -0.0245 & 1.3434 \\
\hline Health & $\begin{array}{l}\text { Average PC } \\
\text { expenses on } \\
\text { tobacco }\end{array}$ & $\begin{array}{l}\text { Average PC } \\
\text { expenses on } \\
\text { milk }\end{array}$ & $\begin{array}{l}\text { Change in } \\
\text { price of } \\
\text { tobacco }\end{array}$ & $\begin{array}{l}\text { Change required } \\
\text { in price of milk }\end{array}$ & $\begin{array}{l}\text { Parameter } \gamma \\
\text { (costs) }\end{array}$ \\
\hline Scenario 1 & 220.5 & 541.9 & 0.064 & -0.0242 & 1.0772 \\
\hline Scenario 2 & 220.5 & 541.9 & 0.301 & -0.0891 & 1.3736 \\
\hline Scenario 3 & 220.5 & 541.9 & 0.408 & -0.1091 & 1.5214 \\
\hline Scenario 4 & 220.5 & 541.9 & 0.428 & -0.1123 & 1.5505 \\
\hline Health & $\begin{array}{l}\text { Average PC } \\
\text { expenses on } \\
\text { tobacco }\end{array}$ & $\begin{array}{l}\text { Average PC } \\
\text { expenses on } \\
\text { food }\end{array}$ & $\begin{array}{l}\text { Change in } \\
\text { price of } \\
\text { tobacco }\end{array}$ & $\begin{array}{l}\text { Change required } \\
\text { in price of food }\end{array}$ & Parameter $\gamma$ (costs) \\
\hline Scenario 1 & 220.5 & 1752.4 & 0.064 & -0.0077 & 1.0471 \\
\hline Scenario 2 & 220.5 & 1752.4 & 0.301 & -0.0303 & 1.2478 \\
\hline Scenario 3 & 220.5 & 1752.4 & 0.408 & -0.0378 & 1.3566 \\
\hline Scenario 4 & 220.5 & 1752.4 & 0.428 & -0.0391 & 1.3785 \\
\hline
\end{tabular}

Source: Author's calculations using ENIGH survey 2016

From Fig. 2a and b, it is also readily apparent that health expenditures is a poor candidate for redistributive purposes. Indeed, the locus of $\delta_{l j}$ lies everywhere below unity, and well below $\gamma_{l j}=1.356$. Under $S_{4}$, Eq. (11) holds for both milk and for food. Indeed, below the threshold, $z \in\left[0, z^{+}\right]$, with both goods and for both orders of stochastic dominance, $S=1$ and $S=2$, we find that $\delta_{l j}=\frac{\overline{C D}_{l}(z)}{\overline{C D}_{j}(z)}>\gamma$. Indeed, using the first-order condition $(S=1)$ in Fig. 2a, both subsidies exceed the cost value (horizontal solid line). Poverty reduction is yet largest with food, since it improves consumption capacity most.

\section{Discussion}

Mexico is one of the few countries for which the prevalence of tobacco consumption is lower among poor households according to our data and to the WHO (Huesca et al. 2019; WHO 2015). This is in stark contrast to countries of lower or similar economic development such as Bangladesh, China, India, the Philippines, the Russian Federation, Ukraine, and Vietnam, where the prevalence of smoking is highest among the poor (Chaloupka and Blecher 2018). 
(a) Order $S=1$.

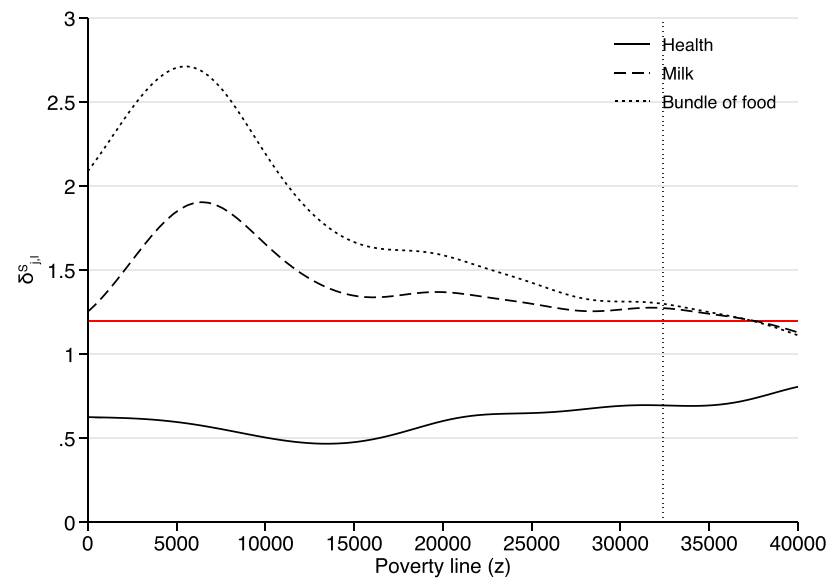

(b) Order $S=2$.

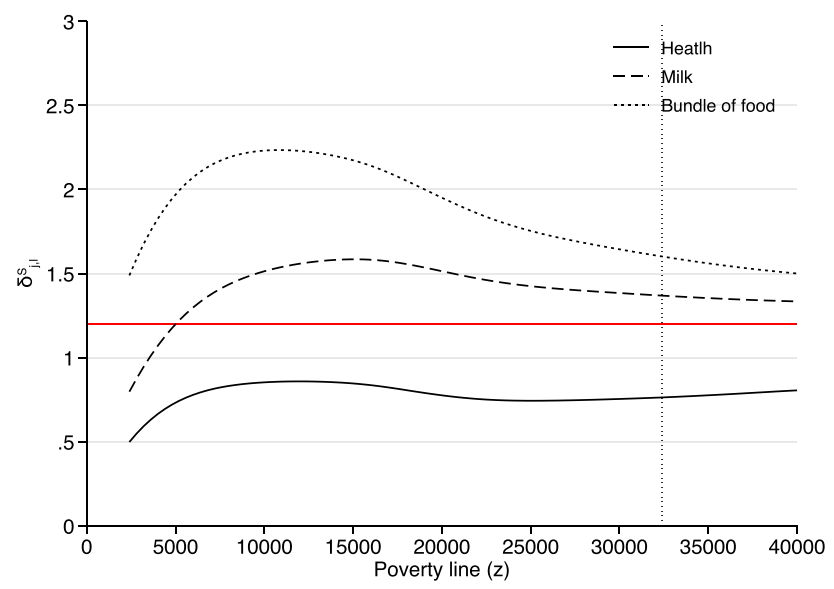

Fig. 2 Dominance consumption ratio of a subsidy on health, milk, and basic food versus tobacco taxes, Mexico 2016. Source: Authors' estimation

In Mexico and in countries considering raising tobacco taxes, authorities ought to be concerned with its potential deleterious effects on poverty. According to our results, light tax increases would do little harm as the overall poverty rate would either remain constant $\left(S_{1}\right)$ or increase from an initial level of $32 \%$ to no more than $33.3 \%\left(S_{2}\right)$. Tax hikes such as those recommended by the WHO $\left(S_{3}\right.$ or $\left.S_{4}\right)$ would 
have larger impacts on poverty, raising the overall poverty rate by 2.5 and $2.6 \%$ among smokers, respectively, but would have no discernible impact on aggregate poverty for the country which would remain constant at $41 \%{ }^{6}$

Our data suggest that the price elasticity of tobacco ranges between -0.25 and -0.75 , while the literature finds that the price elasticity of health expenditures is around -0.95 (Foster and Shorrocks 1988a, b). Based on these estimates, our simulations show that converting the additional tax revenues accruing from a sizable tax hike into a subsidy on specific consumption goods can mitigate to a large extent its potential deleterious effects on poverty strengthening progressivity of the tobacco tax, as well.

Recently, some have advocated subsidizing health expenses for middle-income countries (Ross et al. 2006; CONEVAL 2019b). Our findings indicate that such a strategy might not be appropriate in Mexico for two reasons. First, over the last decade, poor households have benefited at no cost from increased health care public expenditures and drug coverage through the Instituto Mexicano del Seguro Social (IMSS). Second, as a result of the higher coverage, health expenditures represent a small share of their total budget. Hence, health care expenses would be little impacted by a public subsidy. On the other hand, greater quality care could be provided using the additional tax revenues. In such a case, subsidizing health items could indeed compensate the increased poverty that would ensue from a higher tobacco tax. According to our estimates, it is best to focus the subsidy on a basket of food items such as beans, milk, corn-tortillas, and eggs, or alternatively on milk, the mainstay of the typical poor Mexican household diet.

Although health expenditures are important in the spending structure of Mexican families, such expenses are more relevant among the non-poor or even among the rich. Hence, one should be concerned with marginal tax reforms that benefit those individuals deserving more of a positive impact on their incomes as a result of the subsidy, as suggested by Dalton's notion of improvement (Mayshar et al. 1995). Departing from the studies of (Yitzhaki and Thirsk 1990; Mayshar and Yitzhaki 1996), there exists no scientific consensus to the best of our knowledge about which excise tax is to be preferred when using a single value judgment. Yet, in the context of Mexico, our analysis suggests that taxing tobacco more aggressively and subsidizing food staples could thus be a win-win policy: in addition to inducing some to reduce their cigarette consumption, or quitting smoking altogether, poor households would enjoy more affordable or better quality food items. Yet, we acknowledge that other tobacco products should be incorporated into the analysis (cigarillos, e-cigarettes, illegal cigarettes, etc.). This would allow to distinguish possible cross-effects among those products and their corresponding impacts on poverty. Unfortunately, such a granular approach would require data that are simply not available at the time of this writing.

\footnotetext{
${ }^{6}$ CONEVAL (2019b) indicates that the ENIGH 2016 survey gives a headcount of $43.6 \%$, while our estimate is $41 \%$. This difference is explained by the extended sample that CONEVAL used including another socioeconomic module in the estimates (ENIGH+MCS), while we only use the ENIGH survey 2016 (our results are +- close).
} 


\section{Conclusion}

This paper is the first to estimate the impact of a reform of the tobacco tax on poverty in Mexico using a novel approach that goes beyond the use of standard absolute poverty indices. We compute Consumption Dominance Curves without and with the implementation of the tax hike to identify who would be hurt most. Assuming tax neutrality, we can determine the implicit subsidy on specific consumption items that would leave poor households almost as well-off once the tax hike is implemented.

If the Mexican authorities were to follow the WHO's recommendations, the tax hike would lead to an increase in poverty of those households with at least one smoker by approximately 2.6 percentage points. Impacted households could be compensated by implementing a pro-poor subsidy focused on the specific food staples of typical Mexican families. According to our results, subsidizing the consumption of beans, corn-tortillas, and eggs would almost entirely mitigate the deleterious effects of the tax reform. Subsidizing milk would also be efficient but to a lesser extent. Contrary to what many have proposed (Ross et al. 2006; CONEVAL 2019b), subsidizing health care and drugs would be inefficient in the Mexican context. This is because poor households already benefit from a minimal social insurance and also because health expenditures represent a small budget item fot this group.

Our results underline the need to account for country-specific institutions and culture when designing policies to reduce smoking or other consumption products exhibiting negative externalities such as alcohol or sugary drinks. Our normative approach can easily be replicated in other countries pursuing similar goals. This research allows to adjust the tax rate for any good and target subsidies in a timely fashion not only linked to the consumption patterns, but also according to the preferences of the decision-makers and the need for additional revenues.

Supplementary Information The online version of this article (https://doi.org/10.1007/s43546-02100141-x) contains supplementary material, which is available to authorized users.

Acknowledgements We are grateful to Dr. Frank Chaloupka, main director of TOBACCONOMICS, for his encouragements, to German Rodriguez for his follow-up on this research, as well as all the members of the Team at RED-SUR, with special emphasis to Cecilia Alemany

Funding This research received external funding from RED-SUR de Economía Aplicada at Montevideo, Uruguay and the Project of TOBACCONOMICS, a BLOOMBERG philanthropies initiative with the grant number CEN-01-2018.

\section{Declarations}

Conflict of interest The authors declare no conflicts of interest.

Ethical approval This article does not contain any studies with human participants or animals performed by any of the authors. 


\section{References}

Araar A, Duclos J-Y, Huesca L (2011) Usage and importance of DASP in Stata. https://www.stata.com/ meeting/mexico11/materials/Huesca.pdf

Chaloupka FJ, Blecher E (2018) Tobacco use makes the poor poorer; tobacco tax increases can change that. A Tobacconomics Policy Brief. Tobacconomics, Health Policy Center, University of Illinois at Chicago, Chicago

Chaloupka FJ, Yurekli A, Fong GT (2012) Tobacco taxes as a tobacco control strategy. Tob Control 21(2):172-180

CONEVAL (2019a) Evolución de las líneas de bienestar y de la canasta alimentaría. https://www.coneval. org.mx/Medicion/MP/Paginas/Lineas-de-bienestar-y-canasta-basica.aspx

CONEVAL (2019b) Medicion de la probreza. resultados a nivel nacional y por entidad federativa 20082019. https://www.coneval.org.mx/Medicion/MP/Paginas/Pobreza-2018.aspx

Duclos J-Y, Makdissi P, Wodon Q (2008) Socially improving tax reforms. Int Econ Rev 49(4):1505-1537

Duclos J-Y, Makdissi P, Araar A (2014) Pro-poor indirect tax reforms, with an application to Mexico. Int Tax Public Financ 21(1):87-118

Foster JE, Shorrocks AF (1988a) Poverty orderings. Econometrica 56(1):173-177

Foster JE, Shorrocks AF (1988b) Poverty orderings and welfare dominance. Soc Choice Welf 5(2/3):179-198

Foster J, Greer J, Thorbecke E (1984) A class of decomposable poverty measures. Econometrica. https:// doi.org/10.2307/1913475

Fuchs A, FJ Meneses (2017) Are tobacco taxes really regressive? Evidence from Chile (World Bank)

Huesca L, Llamas L, Calderon C (2019) Distributional effects on excise taxes among Mexican households. Contad y Adm 64(3):107

Huesca L, Llamas L, Araar A, Molina O (2020) Analysis of tobacco taxation and simulations in mexico using LATINMOD. CIAD. https://tobacconomics.org/wp-content/uploads/2020/05/CIAD.-Analysis-of-tobacco-taxation-and-simulations-in-Mexico-using-LATINMOD-1.pdf

Husain MJ, Datta BK, Virk-Baker MK, Parascandola M, Khondker BH (2018) The crowding-out effect of tobacco expenditure on household spending patterns in Bangladesh. PloS One 13(10):15

INEGI (2017) Encuesta nacional de ingresos y gastos de los hogares. Aguascalientes, Méxicó

Jimenez-Ruiz JA, Sáenz De Miera B, Reynales-Shigematsu LM, Waters HR, Hernández-Ávila M (2008) The impact of taxation on tobacco consumption in Mexico. Tob Control 17(2):105-110

John RM, Ross H, Blecher E (2012) Tobacco expenditure and its implications for household resource allocation in Cambodia. Tob Control 21(3):341-346

Makdissi P, Wodon Q (2002) Consumption dominance curves: testing for the impact of indirect tax reforms on poverty. Econom Lett 75(2):227-235

Mayshar J, Yitzhaki S (1995) Dalton-improving indirect tax reform. Am Econ Rev 1:793-807

Mayshar J, Yitzhaki S (1996) Dalton-improving tax reform: when households differ in ability and needs. J Public Econ 62(3):399-412

Ross H, Chaloupka FJ (2006) Economic policies for tobacco control in developing countries. Salud Pública de México 48(S1):113-120

Ross H, Stoklosa M, Krasovsky K (2012) Economic and public health impact of 2007-2010 tobacco tax increases in Ukraine. Tob Control 21(4):429-435

Sáenz de Miera Juárez, B, CM Guerrero López, J Zúñiga Ramiro, and S Ruiz Velasco Acosta (2013) Impuestos al tabaco y políticas para el control del tabaco en Brasil, México y Uruguay. resultados para México. Fundación Interamericana del Corazón

San S, Chaloupka FJ (2016) The impact of tobacco expenditures on spending within Turkish households. Tob Control 25(5):558-563

Schluter C, Wahba J (2010) Are parents altruistic? evidence from Mexico. J Popul Econ 23(3):1025-1046

WHO (2009) WHO report on the global tobacco epidemic 2009: implementing smoke-free environments. World Health Organization, Geneva

WHO (2011) WHO report on the global tobacco epidemic 2011: warning about the dangers of tobacco. World Health Organization, Geneva

WHO (2013) WHO report on the global tobacco epidemic 2013: enforcing bans on tobacco advertising, promotion and sponsorship. World Health Organization, Geneva

WHO (2015) WHO report on the global tobacco epidemic 2015: raising taxes on tobacco. World Health Organization, Geneva 
WHO (2019) WHO report on the global tobacco epidemic 2019: offer help to quit tobacco use. World Health Organization, Geneva

Yitzhaki S, Thirsk W (1990) Welfare dominance and the design of excise taxation in the Cote d'ivoire. J Dev Econ 33(1):1-18 